\title{
ARGUMENTOS COMESTIBLES La construcción retórica de la percepción pública de los alimentos transgénicos*
}

\author{
PALOMA HERRERA RACIONERO
}

Universidad Politécnica de Valencia

\section{PALABRAS CLAVE ADICIONALES}

Alimentos genéticamente modificados, Estrategias retóricas, Pensamiento ilustrado/ romántico.

\author{
ADDITIONAL KEYWORDS \\ Genetically Modified Food, Rhetorical Strategies, \\ Illustrate/Romantic Thought.
}

RESUMEN. El objetivo de este trabajo es analizar cómo se construyen los diferentes tipos de argumentos orientados a crear una u otra percepción pública de los alimentos transgénicos. No obstante la aparente novedad de este tipo de alimentos, dichos argumentos pueden asimilarse a dos tipos fundamentales de formaciones discursdivas de amplia tradición ante las diferentes aportaciones de la ciencia. Al modelar nuestro análisis sobre estas dos estrategias retóricas — que llamamos ilustrada y romántica-se ponen de manifiesto los presupuestos latentes de los agentes sociales y las preconcepciones que estos agentes tratan de inducir en la opinión pública, así como una serie de importantes matices y orientaciones que suelen escapar a un análisis en términos de 'pros' y 'contras' de los alimentos transgénicos.

ABSTRACT. The main goal of this paper is to analyze how the different types of reasons are constructed in order to create one public perception or another about genetically modified food. Despite the apparent newness of this kind of foods, these reasons can be assimilated to two fundamental discourse formations with ample presence in all the scientific discoveries. When modelling our analysis on these two rhetorical strategies - that we called 'illustrate' and 'romantic' - the latent presuppositions of the social agents considered and the preconceptions that these agents try to induce in the public opinion are shown. It is also shown a series of important shades and directions that usually escape to the more common analysis in terms of 'pros' and 'cons' genetically modified food.

\footnotetext{
${ }^{*}$ El material cualitativo utilizado para la realización de este trabajo procede del proyecto nacional I+D+I "El impacto de la biotecnología en España: La percepción social de las aplicaciones alimentarias" (Bio 2000-0947), dirigido por Jesús Contreras, Universidad de Barcelona.

Las ideas expuestas en este artículo han sido presentadas por la autora en el VIII Congreso Español de Sociología celebrado en Alicante los días 23-25 de septiembre de 2004.

E-mail: paherra@esp.upv.es
}

Revista Internacional de Sociología (RIS)

Tercera Época, No40, Enero-Abril, 2005, pp. 183-205. 


\section{INTRODUCCIÓN}

Los alimentos transgénicos, ¿son naturales o artificiales, saludables o dañinos, seguros o peligrosos? ¿Qué dice de ellos la ciencia? ¿Pueden distinguirse los argumentos y pruebas científicas sobre estos alimentos de los intereses económicos, los prejuicios culturales o las más amplias visiones del mundo de los agentes en juego? Dada la relativa novedad en el mercado de los organismos genéticamente modificados (OGMs) podría pensarse que la percepción que los consumidores se hagan sobre los alimentos elaborados a partir de ellos depende de la información que vayan recibiendo sobre sus características particulares y del progresivo conocimiento que se vaya adquiriendo sobre este tipo de alimentos. De ser efectivamente así, cabría esperar que los discursos en torno suyo presentaran información novedosa y argumentos ceñidos a sus propiedades originales.

No obstante, nuestro análisis de lós argumentos en juego revela más bien unos tipos de formaciones discursivas ${ }^{1}$ y de recursos retóricos que, lejos de aportar novedad alguna, parecen más bien prolongar tópicos argumentativos que se vienen reproduciendo desde hace un par de siglos. Desde que, en los albores de la modernidad, la ciencia se constituyó en pieza clave del progreso y el bienestar, cuando el debate sobre cualquier innovación científica llega a alcanzar cierto grado de publicidad, los argumentos con que se pretende orientar a la opinión pública parecen anudarse sistemáticamente en torno a uno $u$ otro de dos polos, configurando dos retóricas tan diferentes como fácilmente identificables. El debate con el que se aspira a dar forma a la percepción pública de los alimentos transgénicos no parece ser una excepción.

A diferencia de otros debates públicos que han involucrado cuestiones científicas ("vacas locas", fecundación in vitro, métodos anticonceptivos, clonación...), el que se mantiene en torno a los OGMs no comienza por ser un debate general al que se fueran incorporando distintos agentes sociales, sino que, desde su comienzo mismo, se trata de una controversia creada y mantenida por unos agentes muy específicos. Efectivamente, en España, la polémica pública sólo salta cuando, a mediados de la década de los 90 , ciertos grupos empresariales ya tienen comprometido un importante volumen de producción y comercialización de semillas transgénicas. Es entonces cuando ciertos grupos, fundamentalmente ecologistas, levantan su voz alertando de sus riesgos potenciales y, a partir de ello, unos y otros, empresas y ecologistas, convocan la intervención de expertos en apoyo de sus respectivas posiciones. Otros agentes, como los sindicatos agrarios (u organizaciones profesionales agrarias), se irán incorporando paulatinamente a

\footnotetext{
${ }^{1}$ Sobre el concepto de "formación discursiva" véase Foucault (1969).
} 
la discusión, y otros más se moverán en alguna de las órbitas de estos agentes principales, como es el caso de las organizaciones de consumidores, de los medios de comunicación y de los partidos políticos, que, por diferentes razones en cada caso, no desarrollan discursos propios sobre el asunto hasta más adelante.

No creemos que pueda decirse que el público actúe como agente en la polémica, pues su papel se limita, en la mayoría de las ocasiones, al de mero receptor de los discursos creados por los agentes mencionados, que, ellos sí, tienen siempre a la opinión pública como destinataria, más o menos explícita, de sus diferentes argumentos.

En un trabajo anterior (Herrera, 2003) hemos analizado el modo en que este debate se crea y organiza, tratando de comprender cómo se construye un debate social, en particular un debate sobre una cuestión altamente técnica, como son los OGMs, sobre la que el consumidor en general no tiene más información ni juicio que el que le pueda llegar desde ciertos grupos restringidos, que son los que están en el origen de la polémica. Esta polémica se expresa como confrontación abierta, no sólo porque toda polémica distribuye necesariamente a los polemistas según criterios beligerantes (pólemos, en griego, significa ya directamente "guerra", "lucha", "combate"), sino porque, en este caso, la propia percepción que los actores tienen de la situación es la de encontrarse "en guerra". Las citas podrían multiplicarse; basten aquí las dos siguientes, una de cada "bando":

"Confiamos en ganar la batalla del Arroz Dorado, a pesar de las dificultades" (ASAJA, junio 2001, p.43) (la cursiva es de la autora).

"Es imposible ganar en este debate sin dividir a la comunidad científico-técnica y atraer a nuestro campo a una parte de los investigadores. (...) El referéndum suizo es sin duda una derrota" (sacado del artículo de Riechmann publicado en la revista Ecologista, otoño 1999, p. 44, y titulado "Lecciones de una derrota") .

Pero no sólo es el debate el que resulta de una construcción premeditada. Los distintos elementos que lo componen también son fruto de una progresiva construcción en el transcurso del mismo: al hilo del debate, las diferentes identidades se van redefiniendo y adquiriendo perfiles diferentes. Se van construyendo así, por medios fundamentalmente retóricos, nuevas identidades en las que cada agente queda definido no sólo por lo que dice de sí mismo y las fronteras que él traza, sino también por lo que de él dicen, esperan, niegan, combaten, atribuyen...los demás. Y el propio objeto de debate, los OGMs, resulta no ser un objeto específico, algo ya dado de una vez por todas, sino más bien un proceso, antes que un producto, que va adquiriendo forma y propiedades en el curso del propio debate. 


\section{RIS}

\section{LAS FUENTES DE ANÁLISIS}

En buena medida, la interpretación del debate en términos de abierta confrontación viene avalada por los evidentes posicionamientos en el mismo por parte de diferentes publicaciones destinadas a dos grupos de ciudadanos especialmente implicados: por un lado, los que tienen que tomar decisiones sobre su uso productivo (los agricultores); y, por otro, los ciudadanos más activamente comprometidos con las decisiones que afectan al medio ambiente (los ecologistas). La relevancia de estos grupos como creadores y/o destinatarios de estos mensajes nos ha inducido a la elección de parte de nuestro material empírico.

Así, una parte de los discursos analizados se ha tomado de documentos y revistas publicadas por sindicatos agrarios ( $u$ organizaciones profesionales agrarias) y grupos ecologistas, así como otras publicaciones dirigidas a agricultores y ganaderos ${ }^{2}$. Si bien las publicaciones e informes de los grupos ecologistas se alinean claramente en uno de los bandos de la polémica, las publicaciones vinculadas al sector agrario, en cambio, se dividen, con no menor claridad, entre los dos campos en disputa: a favor de los OGMs se decantan el sindicato agrario ASAJA y las revistas Agricultura, Vida Rural y Agroalimentaria; en contra se encuentran los sindicatos UPA y COAG.

Además, $\mathrm{y}$ a partir de dichas publicaciones, hemos constatado que en el debate participan reiteradamente un grupo no muy numeroso de expertos, y a algunos de ellos nos hemos dirigido para obtener discursos más directos con los que tratar de completar, profundizar y matizar nuestro análisis. Son, en total, quince expertos (a los que, por razones obvias, mantendremos en el anonimato, refiriéndonos a ellos a lo largo de este trabajo como "actor en el debate" o por sus respectivas siglas identificativas), claramente posicionados en una u otra alternativa ${ }^{3}$, implicados directamente por profesión y actividad en temas relacionados con la biotecnología en general y con los OGMs en particular. A través de entrevistas abiertas, se ha buscado que los actores hablen libremente, que emitan un discurso subjetivado. Sin guión, durante 45-60 minutos, hemos intentado que sean los propios entrevistados los que decidan tanto el contenido, como la forma de expresión, que sean ellos

\footnotetext{
${ }^{2}$ Estos documentos y revistas son: UPA, documentación interna y revista La Tierra del agricultor y el ganadero, enero, 1998-junio 2002; COAG, documentos internos, enero, 1997-junio, 2002; revista ASAJA, enero, 1998-junio 2002; Agricultura, enero, 1998-junio, 2001; Vida Rural, enero, 1997-junio, 2000; Agroalimentaria, enero, 1998-junio, 2002 Gaia-Ecologista, 1995-enero 2002; World Watch, octubre, 1996-diciembre 2000; The Ecologist, mayo 2000-enero, 2001, informes monográficos de Greenpeace, 1996-2002; y Ecologista, 1998-2002.

${ }^{3} \mathrm{La}$ absoluta falta de ambigüedad de estos posicionamientos nos ha llevado a identificarlos por su opción "a favor"' (F.1, F.2, etc.) o "en contra" (C.1, C.2, etc.) de los OGMs, lo que también facilita al lector ciertas claves de lectura.
} 
los que den forma a la entrevista sin más pautas'ni limitaciones que las propias de cada uno de los actores y del medio de expresión (entrevistas grabadas).

\section{DOS VISIONES DEL MUNDO}

La variedad de discursos en torno a los OGMs puede analizarse, más allá de su simple adscripción a favor o en contra de los mismos, desde otras categorías más comprensivas que nos permitan inferir de ellos ciertos presupuestos y actitudes en los que se basan y que les orientan ${ }^{4}$; presupuestos y actitudes que no se deducen inmediatamente del mero análisis discursivo de los textos y entrevistas. En particular, parece especialmente relevante el uso de aquellas categorías que se mueven en torno al eje ilustración/ romanticismo, como dos maneras fundamentales de entender el mundo desde que, en el siglo XVIII, la ciencia se convierte en un factor decisivo de los cambios sociales. Bien entendido que tanto el que llamamos pensamiento ilustrado como el pensamiento romántico no se consideran aquí formas esenciales de ser, ni siquiera dos modos históricos de pensar que tuvieran realidad en sí mismos; más bien los concebimos al modo de los tipos ideales weberianos, como categorías conceptuales que sólo se justifican en la medida en que hagan aflorar, en la multitud de discursos sobre los OGMs, rasgos no evidentes a simple vista y obtener así otros criterios para su análisis, comprensión y clasificación que antes hubieran podido pasar desapercibidos. Las que llamaremos "ideología ilustrada" e "ideología romántica" deben entenderse, pues, como construcciones conceptuales destinadas específicamente a procurar una mayor comprensión del asunto enfatizando lo que en él es relevante desde una cierta perspectiva.

Seguiremos aquí las caracterizaciones de los imaginarios romántico e ilustrado que hace Bloor (1998: 110-113), si bien reordenaremos, a efectos heurísticos, alguno de los rasgos que él señala, con objeto de que resalten más ciertos aspectos del debate concreto al que aplicaremos este modelo interpretativo. Conviene aclarar, una vez más, que este modelo es fundamentalmente heurístico, antes que descriptivo. La cuestión no es intentar describir en qué consisten realmente $e^{5}$ la Ilustración y el Romanticismo, tal y como se dieron en la filosofía o en el arte en

\footnotetext{
${ }^{4}$ Un interesante estudio sobre los valores subyacentes en el conflicto de la ingeniería genética se puede encontrar en Todt $(2003,2004)$.

${ }^{5}$ Por otra parte, en qué consistan realmente ambos movimientos es cosa aún arduamente debatida entre los especialistas, que tan pronto destacan para cada uno tanto unas características como otras, cuando no afirman las opuestas a las señaladas por algún otro erudito. Basta ver, para el romanticismo, Berlin (2000) y, para la ilustración, la contraposición entre sus habituales descripciones idílicas y las desarrolladas por Bauman (1997), prolongando la discusión iniciada por Adorno y Horkheimer en La dialéctica de la Ilustración.
} 
una época histórica concreta $-\mathrm{y}$ tal y como, supuestamente, se darían también en el presente debate-, sino fabricar dos tipos ideales que sólo se justifican $a$ posteriori, es decir, en la medida en que nos hayan posibilitado descubrir ciertos aspectos de las posturas en debate que antes habían permanecido opacos. El "imaginario ilustrado" y el "imaginario romántico" se hacen, por tanto, intervenir aquí a título de artefactos o herramientas que, como el microscopio o el concepto de átomo, hacen ver lo que previamente no se veía.

A estos efectos, caracterizaremos ambos imaginarios ${ }^{6}-\mathrm{y}$, en consecuencia, las formaciones discursivas correspondientes- por un juego de notas opuestas entre sí, al objeto de agudizar esa dimensión heurística.

1. En primer lugar, para el imaginario ilustrado, naturaleza y sociedad son dos realidades nítidamente diferenciadas, cuando no antagónicas. Existe un estado de naturaleza, previo al estado propiamente social, que se construye sobre el primero $\mathrm{y}$, en buena medida, por negación de él. El discurso sobre este estado de naturaleza y sobre el contrato social que se construye sobre él se complementa con el de unos derechos naturales universales e inalienables, como el derecho a la propiedad o a la libertad. Esa oposición entre naturaleza y sociedad justifica la necesidad de intervenir en la primera a efectos de constituir y mejorar la segunda. La naturaleza se percibe así, por una parte, bien como una entidad pasiva y desanimada, bien como una amenaza, estando justificados, en cualquiera de ambos casos, su control y dominio progresivos. Otra consecuencia se cifra en que la naturaleza se percibe como una esfera autónoma cuya alteración no tiene por qué repercutir en esa otra esfera que es la propiamente social.

Para el imaginario romántico, en cambio, la idea de una naturaleza humana presocial se sustituye por una naturaleza esencialmente social. Naturaleza y sociedad son dos ámbitos interpenetrados, que se constituyen el uno al otro. No se concibe, pues, que se pueda alterar la naturaleza sin producir también alteraciones en un hombre que se percibe como prolongación de ella. A su vez, si lo social se percibe como natural, también lo natural se piensa en términos sociales. A la naturaleza se le atribuyen así rasgos propiamente sociales y antropomórficos, como es la intima solidaridad y trabazón entre sus miembros o su vitalismo (ahora ya no percibido como la amenaza proveniente de un antagonista, sino como pujanza o sabiduría), su inteligencia y su vulnerabilidad.

2. En segundo lugar, el modo de pensar ilustrado es atomista e individualista. Tanto la naturaleza como la sociedad, el lenguaje o cualquier otro fenómeno, se

\footnotetext{
"Algunas de estas ideas aparecen expuestas en la comunicación "El debate en torno a los OGM", presentada en el IV Congreso Internacional de Antropología, Barcelona, 2002 por Díaz Méndez y Herrera Racionero.
} 
conciben como conjuntos de elementos individuales e inconexos, cuya "esencia" no se altera al reunirse entre sí. Los "todos", que serían la naturaleza y la sociedad, se obtienen así por mera agregación de sus partes constitutivas, que, se supone, poseen naturaleza independiente por sí mismas. Puede, por tanto, modificarse o sustituirse cualquiera de esas partes individualizadas sin que, por ello, se vea alterado el conjunto o cualquiera de las otras partes. Las metáforas mecánicas son entonces las dominantes en su discurso típico.

El pensamiento romántico es, por el contrario, un pensamiento holista. Las diferentes entidades, tanto naturales como sociales, no tienen existencia y significado individual independientemente de los todos en que se integran y les dan sentido. Las entidades sociales no se tratan como meras colecciones de individuos, sino como depositarias de propiedades (espíritu, tradición, ciertas características específicas) que lo son también de los miembros que las integran. Tampoco las entidades naturales pueden descomponerse en piezas que mantienen su identidad fuera de ellas, pues deben al todo lo que son. En consecuencia, es imposible alterar cualquiera de las partes sin que las otras, y el todo que las constituye, se vean también radicalmente alteradas. $\mathrm{Si}$, en el pensamiento ilustrado, naturaleza y sociedad se conciben de forma mecanicista, según su analogía con la máquina, en el romántico es la analogía con el organismo vivo la que domina.

3. El tercer rasgo del imaginario ilustrado es su perspectiva universalista y ahistórica. Las partículas individuales que componen tanto la naturaleza, como la sociedad no varían según su situación en los contextos concretos o según ciertos momentos o épocas, sino que mantienen su identidad en todo momento y ocasión. Las variaciones históricas o geográficas son secundarias respecto de la intemporalidad y universalidad fundamentales que se presuponen. Ciertamente, existe el progreso, pero se trata de un progreso de un "lo mismo" que siempre ha existido y ha sido igual para todos los grupos humanos, ya sea la razón, la técnica o el bienestar. Los ideales y principios abstractos (tanto de la ciencia como del derecho o la moral) son, pues, de aplicación intemporal y general, independientemente de las circunstancias.

Por oposición, el imaginario romántico enfatiza lo histórico y lo concreto. Los objetos, acontecimientos, momentos o instituciones no se perciben en su referencia a un ideal abstracto e intemporal, sino en su singularidad y complejidad, siempre referidos a sus particulares contextos y a los procesos temporales en los que se insertan. Las variaciones históricas o geográficas, lejos de ser meras variaciones de lo mismo, confieren a los acontecimientos cierta irreductibilidad e incomparabilidad. Ni lo natural, ni lo social obedecen a leyes abstractas y universales, pues las formas de reaccionar y adaptarse son diferentes según el lugar y el momento.

4. En cuarto lugar, el tipo ilustrado sostiene una fe casi ciega en la razón, y en particular, en su forma más perfeccionada, la razón científica. La razón es una 
fuerza independiente que, dejada a sí misma, no puede traer sino bienestar y progreso, por lo que cualquier descubrimiento científico o construcción tecnológica no deben ser sometidos al juicio de otros valores (éticos, emocionales, políticos...), por tanto deben aplicarse por encima de cualquier otra consideración. La bondad o maldad de las invenciones o prácticas dependen antes de su verdad (una verdad que se supone que es la ciencia la que la certifica), que de cualesquiera otras consideraciones sociales, culturales o morales. Este racionalismo típicamente ilustrado se prolonga también en su deductivismo abstracto: los casos concretos se aclaran al ponerlos en relación con principios abstractos y racionales; la verdad no le viene a lo singular de su interior, ni de su diferencia, sino de participar en una verdad general de la cual es mero ejemplo o ilustración. La razón como ideal orienta, pues, tanto la conducta como la comprensión de las cosas. Consecuencia de ello es la desvalorización de las formas comunes de expresión y de formas de conocimiento que se consideran no científicas, como el conocimiento ordinario o los saberes tradicionales, entre los que se encuentra el saber campesino.

Para el pensamiento romántico, sin embargo, la razón no es la categoría suprema a la que deban subordinarse cualesquiera otros valores, ya sean valores morales, estéticos o emocionales. Los criterios de verdad y racionalidad científica son sólo unos más entre otros criterios. Y es la consideración conjunta e interrelacionada de todos ellos la que debe orientar las decisiones. La búsqueda de un ideal racional no es el único criterio de conocimiento ni de acción colectiva ni individual ${ }^{7}$. Como tampoco es un modo adecuado para la comprensión de algo el prescindir de sus rasgos propios y de sus complejas conexiones para poder reducirlo a caso particular deducible de un principio o ley abstracta y general. Para el romántico, enjuiciar la complejidad de los hechos desde sus idealizaciones abstractas es un inaceptable reduccionismo. El conocimiento ordinario y los saberes tradicionales, obtenidos por una mezcla de experiencias, intuiciones y razonamientos informales, resultan así revalorizados, pues se consideran más sensibles a la complejidad de las situaciones locales y concretas, más adaptados a las diferencias.

5. El quinto, y último rasgo, afecta a la diferente concepción del tiempo en cada uno de ambos imaginarios. En el imaginario ilustrado, el tiempo se concibe como una línea recta orientada hacia el futuro y que deja siempre atrás el pasado. Como quiera que ese avance lo es necesariamente de la razón, el futuro sólo puede concebirse como el lugar de lo mejor y, recíprocamente, el pasado se carga de valoraciones negativas. El tiempo es tiempo de progreso. La razón en general, y la razón científica en particular, se consideran vectores intrínsecos de progreso y

\footnotetext{
${ }^{7}$ Esta reconsideración del valor de la racionalidad científica, que quizá arranque de la obra de Nietzsche, se desarrolla con un sesgo de especial interés en Fox Keller, 1991. Véase también Ibáñez (2001) (especialmente, "La acción colectiva dice adiós a Descartes").
} 
de emancipación, en lo que es una concepción netamente teleológica de la historia. De ahí que una de las retóricas propias de las formaciones discursivas ilustradas sea la que se ha llamado retórica de la esperanza (Mulkay, 1994). En consecuencia, los discursos ilustrados son marcadamente prescriptivos. No se atiende tanto a lo que es (presente) ni a lo que ha sido (pasado), como a lo que debe ser (futuro). El tiempo presente se percibe como tiempo útil en función de un futuro que es el que le da sentido: es un tiempo cargado de "retos", de "proyectos", de "posibilidades" y de "promesas". El universalismo abstracto e ideal, antes mencionado, permite crear una distancia con la realidad presente y concreta. Esta distancia permite separar valores (ideales) y hechos (reales), así como permite también poder tanto criticar la realidad pasada y actual, como definir objetivos a cumplir.

Esta presuposición del tiempo como progreso del bienestar y la razón se pone bajo sospecha en la ideología romántica. El tiempo no tiene por qué estar necesariamente orientado hacia mayores cotas de bondad, racionalidad y emancipación. El futuro no tiene por qué ser mejor: incluso, con frecuencia, es peor. De ahí que la que se ha llamado retórica del miedo (Mulkay, 1994) sea habitual en este tipo de discursos. Frente al tiempo lineal ilustrado, el tiempo del imaginario romántico, en su formulación más típica, sería más bien un tiempo circular, donde - a semejanza del tiempo campesino-los ciclos se cierran y donde no puede hablarse propiamente de progreso o retroceso en el saber o las costumbres. Y cuando predomina una concepción lineal, el romántico invierte los valores ilustrados asociados a cada tramo temporal. El presente tiene valor por sí mismo y no en función de un futuro ideal para el que no sería sino una mera etapa. Y el pasado adquiere una valoración positiva como lugar en el que arraigan y se legitiman esas otras prácticas y formas de razón, distintas de las científicas, que son los saberes y haceres tradicionales. En consecuencia, en las formaciones discursivas románticas predomina lo descriptivo sobre lo prescriptivo. No es el deber ser, dictado por el ideal abstracto y su distancia respecto de la realidad, el que marca los discursos, sino el asi es. Son las diferentes realidades concretas que son (en el presente) y que han sido (en el pasado) las que se consideran y las que tienen valor por sí mismas. El discurso romántico también es, ciertamente, moralizante, pero la suya es una moralidad reactiva frente a la moralidad intrínseca propia del discurso ilustrado que hace del ideal abstracto un deber por sí mismo. El carácter descriptivo tiende así a recoger la conexión entre valores y hechos, entre la complejidad de la realidad y los distintos modos de evaluarla, que no se limitan a los de una evaluación racional.

Esta polaridad entre ambos tipos ideales ha sido aplicada de manera fructífera por Bloor $^{8}$ para revelar los componentes sociales y culturales que se esconden tras lo

\footnotetext{
${ }^{8}$ Bloor (1998). En especial el capítulo IV titulado "Conocimiento e imaginario social: un estudio de caso".
} 
RIS

que, a primera vista, pudiera parecer un mero debate técnico entre epistemólogos. Así, las diferentes posiciones-sobre lo que es la ciencia y sobre su dinámica interna-que han mantenido Popper y Kuhn se muestran, desde esta perspectiva, como la concreción, en un debate científico, de dos maneras generales de entender no sólo la ciencia, sino el hombre y el mundo en general: las maneras de pensar ilustrada y romántica, respectivamente. Sólo esta inmersión de los aspectos técnicos del debate en un marco más amplio nos aporta el suficiente grado de comprensión del mismo y nos permite trascender las habituales caracterizaciones en términos de "a favor" y "en contra" del asunto objeto de discusión, es decir, de los alimentos OGMs: "Creo que no se entiende bien la naturaleza del debate epistemológico [y otro tanto podría decirse sobre cualquier otro debate, como el de los OGMs que aquí enfocamos] si no se piensa como expresión de profundos intereses ideológicos en el seno de nuestra cultura" (Bloor, 1998: 101).

Pues bien, del mismo modo en que procede Bloor en su interpretación de lo que parecería un mero debate epistemológico, la consideración de ambos imaginarios puede hacer decir a los discursos sobre los OGMs analizados algo más de lo que parecen decir. En la medida en que ello sea así, puede considerarse que el debate va más allá de la mera discusión sobre la bondad o los peligros de los productos transgénicos, más allá de la propia biotecnología, para traslucir dos formas de entender el mundo.

Tras aplicar este modelo polar a nuestro caso, debemos avanzar algunas observaciones que se seguirán del análisis del conjunto del material estudiado. La primera estriba en que, en los diferentes discursos, los cinco rasgos antes definidos aparecen entremezclados, pues incluso en su mera exposición formal anterior muchos elementos se siguen lógicamente unos de otros. La segunda observación apunta a que, si bien las características ideales que definen los imaginarios ilustrado y romántico se corresponden, con notable precisión, con los elementos fundamentales de los discursos "a favor" y "en contra" de los OGMs, en el caso de este último se dan algunas singularidades. Por un lado, los elementos que definen el imaginario ilustrado, al haberse instituido en muchos aspectos como ideología dominante, impregnan en gran medida el imaginario occidental actual en su conjunto, incluido el imaginario de quienes más pudieran parecer opuestos a él, como son los oponentes al uso de los OGMs. Por otro lado, así como las formaciones discursivas de los "pro" presentan fuertes regularidades y una considerable homogeneidad (lo que acaso pueda explicarse por el hecho de que los cinco rasgos del imaginario ilustrado presionan todos en este sentido), en las de los "anti" se aprecia mayor heterogeneidad, en parte quizá debido a que ésa es una característica presente en varios de los propios rasgos del imaginario romántico, en parte debido también, seguramente, a los diferentes grados de impregnación-a que hacíamos referencia-de este imaginario por elementos del imaginario ilustrado. 
Una tercera observación, referida también a esta mezcla de rasgos de uno y otro tipo, apunta a otra posible causa. Al orientarse cada discurso hacia un doble interlocutor (el antagonista y el consumidor) con frecuencia se entreveran en él temas inducidos por cada una de ambas orientaciones. Lo que un interlocutor argumenta con la vista puesta en su oponente le lleva a resaltar esa oposición, por lo que hace destacar entonces los rasgos característicos de su propio imaginario; pero aquella parte del discurso que se orienta al público (consumidor) se apropia, con frecuencia, de aquellos elementos del oponente que, a su juicio, pueden mover hacia su terreno a ciertos lectores u oyentes. Tal ocurre, por ejemplo, cuando un discurso típicamente ilustrado incorpora una visión dinámica de la naturaleza, que es un elemento del discurso romántico, para enfatizar su cara más amenazante y justificar así la necesidad de someterla. En estos casos se impone un análisis más minucioso que sea capaz de distinguir lo que son las regularidades de fondo que caracterizan cierta formación discursiva, de lo que son préstamos ocasionales tomados de otras formaciones discursivas antagónicas que, a efectos persuasivos, se subordinan y ponen al servicio de la formación discursiva principal.

Aclarado esto, podemos señalar cómo entre los mismos protagonistas hay quienes aprecian la presencia en el debate de dos visiones del mundo, tal como se refleja en las siguientes transcripciones:

"Existen distintas visiones del mundo en realidad, no del problema concreto. Hay una contraposición entre un productivismo que básicamente ignora la cuestión de los límites y dice que no hay que preocuparse por eso porque vamos a resolver los problemas, uno detrás de otro. $\mathrm{O}$ un pensamiento que reconoce que existen límites y que los seres humanos, a parte de poder saltarnos los límites tecnológicamente, también podemos hacer otras cosas, por ejemplo desarrollar las posibilidades del lenguaje y simbólicas" (C.1) (la cursiva es del autor).

"Pero la oposición es de fondo, que esto es intrínsecamente malo porque estás cambiando el orden de la naturaleza, y esto corresponde a una visión de la naturaleza, de lo que es la naturaleza, que yo definiría una naturaleza más estática, como de alguien que contempla la naturaleza, frente a una visión que a lo mejor me viene mal formado por la carrera o por lo que sé, como más progresiva, que aquí hay una evolución que se va cambiando y esta evolución está en el origen de la naturaleza y estamos en cambio. Yo no creo en la agricultura bucólica y así porque no la he visto en ningún sitio, pero bueno son dos. Estamos en dos visiones contrapuestas porque son dos visiones de la naturaleza distintas, con lo cual son debates muy raros, muy en paralelo, porque no hablamos de lo mismo, no hablamos ni los unos ni los otros de lo mismo, del fondo" (F.5) (la cursiva es del autor).

Desde uno y otro lado se considera que lo que se enfrenta no son dos valoraciones de los OGMs en particular, sino "dos visiones del mundo" en general. Este término, 
antecesor del concepto de "imaginario" que aquí utilizamos, era habitual en la filosofía y sociología alemanas y es el que utilizan ambos informantes para referirse también, significativamente, al modo de pensar y sentir, no de los expertos, sino del hombre común socializado en una cultura determinada.

También es significativo que F.5 afirme que "no hablamos de lo mismo". Bajo el mismo nombre existen objetos diferentes, las mismas palabras tienen significados distintos en una y otra formación discursiva, lo que es una de las principales señales de que son dos imaginarios los que se enfrentan. Puede extrañar la atribución por este actor de "una visión de la naturaleza más estática" a quienes, en principio, se caracterizan por percibirla de modo más dinámico. La extrañeza ya no es tanta cuando observamos que, como apuntábamos antes, la reivindicación del dinamismo de la naturaleza se pone aquí para identificar los cambios introducidos en los OGMs con los cambios que la naturaleza introduce por sí misma. La curiosa alusión a ese dinamismo en términos de "una visión más progresiva" no puede dejar de traslucir la proyección sobre la naturaleza de la valoración ilustrada del progreso.

\section{ALIMENTOS TRANSGÉNICOS: ¿ALIMENTOS IMAGINARIOS?}

Nos encontramos así de lleno en el análisis del primer rasgo que caracteriza ambos imaginarios. Pese a este tipo de alianzas coyunturales con la naturaleza, el discurso de quienes promueven los OGMs asume el elemento ilustrado de una naturaleza en contraste con la cual se perfila lo específicamente humano y social.

"Ha habido importantes mejoras en la resistencia a enfermedades e insectos y en la tolerancia a una variedad de estrés abióticos, especialmente en toxicidades en suelos, pero debemos seguir esforzándonos en aumentar al máximo el potencial genético si queremos afrontar el reto de la demanda de alimento prevista para el futuro" (Agricultura, abril, 2002, p. 346) (la cursiva es del autor).

La naturaleza es lugar de "enfermedades e insectos", frente al que hay que "seguir esforzándonos" y aumentar la "resistencia". Son también causas naturales, y no políticas o económicas, las que privan de alimentos a buena parte de la población (como aquel Tercer Mundo al que la naturaleza había privado de vitamina A), por lo que la naturaleza lanza un "reto" que debe afrontar la humanidad para constituirse - y sobrevivir - como tal. En ocasiones este enfrentamiento entre sociedad y naturaleza llega a dibujar cuadros de colores nítidamente hobbesianos:

"Yo pediría que cuando Arguiñano recomienda el perejil pues que se hiciera una investigación de los efectos de los soralenos que hay en el perejil porque los soralenos 
son cancerígenos. $\mathrm{O}$ las setas llamadas comestibles tienen.... Las patatas fritas tienen acrilamida o montones de aceite tienen benzopireno y no se exige ni que vayan etiquetados diciendo que tienen benzopireno, que es un riesgo conocido, ni se exige que se pongan las partes por millón que lleva para que el consumidor diga "voy a comprar un aceite que lleve menos benzopireno". Porque, claro, lo de informar al consumidor, eso es retórica. El consumidor no está dispuesto a perder dos segundos en enterarse de qué es de lo que se tiene que enterar y ya en lo que haya probado hay un montón de cosas que haría bien en enterarse" (F.4).

"O como el riesgo que tienen (los agricultores ecológicos) que quieran un incremento en un maíz que quisieras cultivar orgánicamente, lo que tienes es un ataque de insectos quieras o no. Lo que te hace es una serie de heridas, a través de las cuales entran hongos que producen microtoxinas que son potentes cancerígenos. Es evidente que cualquier analítica en un maíz orgánico da un nivel de microtoxinas, mientras que en un maíz transgénico te da cero" (F.1).

Como en la película de Ridley Scott, Alien, el octavo pasajero, la naturaleza es un extraño, un extraño amenazante, ese alien que puede adoptar las formas más diversas e incluso familiares, ya sea la del perejil o la de la aparentemente inocua patata frita. Para los "anti", por el contrario, naturaleza y sociedad se interpenetran, tanto materialmente como a través de las figuras retóricas que suelen emplearse para nombrar a una en términos de la otra:

"En esta agricultura el conocimiento se comparte, las demás especies y plantas son parientes, no 'propiedad' y la sustentabilidad se basa en la renovación de la fertilidad de la tierra, en la renovación y en la regeneración de la biodiversidad (V. Shiva en The Ecologist, enero 2001, p.36) (la cursiva es del autor).

La especie humana se percibe como una más entre "las demás especies y plantas" que a su vez se ven como "parientes" de aquélla. La naturaleza alberga relaciones de parentesco (como también expresa el lenguaje común al hablar de plantas de "la misma familia" o de filiaciones entre unas y otras) al tiempo que la especie humana es una - otra- especie natural. Asímismo, el empleo de un término ambiguo como el de "fertilidad"(válido tanto para humanos como para no humanos, al hablar de la "renovación de la fertilidad de la tierra") contrasta con el de "aumentar al máximo el potencial genético" que expresa una marcada distancia retórica con una naturaleza semejante a un sistema termodinámico cuyo "potencial" hubiera de maximizarse. En la siguiente cita, la interrelación entre ambas entidades no se afirma sólo en la "armonía" entre ambas, sino también en la evocación de la asociación que se hacía en la antigua Grecia entre la armonía propia del cosmos y la justicia humana, entendida como armonía entre las partes que integran la sociedad: 


\section{RIS}

"Nuestra relación con la nàturaleza no puede seguir basándose en la idea de explotación y dominación. Queremos una humanidad justa en armonía con la naturaleza. Ecologistas en Acción trabajará en favor de una nueva ética en las relaciones de los seres humanos con los demás seres vivos y sus hábitats. Es preciso reconocer unos derechos elementales a los animales, que nunca más deben recibir sufrimientos gratuitos como objeto de diversión, de tradición o por ser usados como objetos ornamentales (Principios ideológicos de Ecologistas en Acción $)^{9}$ (la cursiva es del autor).

Por otra parte, aquí se manifiesta la impregnación a que hacíamos referencia de un discurso típicamente romántico con elementos prestados de formaciones discursivas ilustradas. El reconocimiento de "derechos a los animales" si, por un lado, reitera esa continuidad entre lo natural y lo social al proyectar sobre los animales instituciones políticas como la del derecho, por otro lado, esa institución política que proyecta es precisamente una de las más típicamente ilustradas: la de un derecho universal, cuyo universalismo se lleva aún más allá de lo que los propiosilustrados hubieran nunca soñado. En el mismo sentido puede interpretarse el que esa extensión de la universalidad del derecho se reivindique incluso frente a la tradición, esa otra institución tan apreciada por el imaginario romántico.

Respecto del segundo punto, destaca la visión ilustrada de la naturaleza como algo inerte, predominando las analogías con una factoría o un almacén:

"La biotecnología (...) contribuirá de forma notoria a la aparición de un nuevo tipo de agricultura 'factoria', donde el hombre pueda modificar las características de las plantas de forma que se consigan variedades con aquellos contenidos nutritivos o comportamientos que se deseen por la industria transformadora o el mercado" (Pedro Barato, presidente de ASAJA, borrador del prólogo al libro La agricultura española ante los retos de la biotecnología, de García Olmedo) (la cursiva es del autor).

Aunque tampoco el pensamiento ilustrado deja de emplear metáforas de personificación para referirse al mundo natural, éstas se subordinan a esa poderosa analogía mecánica o maquínica que concibe los organismos vivos como entes compuestos de piezas que pueden alterarse, sustituirse o repararse a voluntad del operario:

"Desde épocas remotas, el hombre ha ido observando la variabilidad natural dentro de las especies vegetales, seleccionando las propiedades que le interesa y anulando las que le son perjudiciales. (...) La biotecnología permite diseñar procesos y productos de una forma específica con unos intereses determinados en casi todos los sectores,

${ }^{9}$ Tomado de http:// www.pangea.org/spie/eahuesca/documen/principi.htm. 
permitiendo utilizar las propiedades de los seres vivos para producir y transformar alimentos, obtener nuevos medicamentos y corregir los problemas de degradación del medio ambiente" (Agricultura, febrero, 1999, p. 133). (la cursiva es del autor).

Esta concepción se manifiesta con toda claridad en la siguiente cita, que lo es de un defensor de los OGMs:

"Usó [el autor] el término de sastrería como alternativo al de ingeniería, porque, como veremos, las operaciones fundamentales de esta vía experimental consisten en cortar $y$ coser (unir piezas) de ADN" (Vida Rural, 1-03-99, s.p.) (la cursiva es del autor).

Frente a esto, los oponentes se definen a sí mismos como "holistas":

"La cosa era escapar más bien de las clases con todo lo que montábamos, porque todavía nos enseñan las cosas como los burros, que sólo miras para adelante y es muy complicado tener una visión holística de lo que es la biología" (C.6) (la cursiva es del autor)

y critican el atomismo dominante:

"Está ahora muy de moda en la ciencia los equipos multidisciplinares, tratar de tener una visión menos atomista de las cosas, pero aún asi json tantas dimensiones! " (C.8) (la cursiva es del autor).

pues ese saber tanto de las partes, y tan poco de los todos en los que se integran, no aumenta el conocimiento sino la ignorancia:

"En el tema de los transgénicos se está llevando hacia un reduccionismo científico. El científico no sabe prácticamente nada de cómo funciona la vida y ni de cómo funcionan las células, y entonces se reduce todo a un gen, a un carácter, y eso no es así (...). Desde el punto de vista de los genes, tú no púedes explicar la complejidad del organismo, tiene que haber otras razones. Entonces se está haciendo un reduccionismo que no sirve para saber cómo está el organismo, y desde ese punto de vista a mí me parece muy imperfecto y yo creo que los problemas de productividad alimentaria no se solucionarán con los transgénicos porque son problemas que tienen que ver con muchos genes y no con uno sólo, y también tienen que ver con el agua, con las horas de sol... Es lo de antes: la complejidad. Desconocemos tanto de tantos factores que no podemos pretender que modificando algunos genes vamos a solucionar todos esos problemas y yo creo que ese reduccionismo nos lleva a un desconocimiento de verdad' (C.4) (la cursiva es del autor).

Para el holismo de los "anti", todo está interrelacionado: tanto los "muchos genes" entre sí como el organismo con su entorno ("el agua", "las horas de sol"...). 
La consideración o no de estos contextos concretos es la que define las diferencias respecto a la tercera nota distintiva. El imaginario ilustrado tiende a borrar las diferencias, enfatizando una visión universalista tanto en el espacio:

"Si se demuestra que la aspirina quita el dolor de cabeza en Nueva York, no pidamos que se demuestre también en Madrid y luego en Alcalá de Henares, y esto es lo que se está haciendo con esto" (F.4) (la cursiva es del autor).

como en el tiempo, que más bien se entiende como un lugar en "lo mismo", que va creciendo y mejorando sin variar esencialmente:

"La mejora genética de las plantas cultivadas es una actividad que se extiende desde los inicios de la agricultura cuando el hombre comenzó a seleccionar las plantas silvestres y siempre ha respondido a la necesidad de obtener más y mejores alimentos que le permitieran nutrirse o fibras que le permitieran vestirse. Como el resto de las actividades humanas, en cada momento de la historia ha ido incorporando los nuevos descubrimientos científicos que aportaban al hombre un mejor conocimiento de las leyes que rigen la Naturaleza. Lo único nuevo que aportan las nuevas técnicas de biotecnología al mejorador (sic) de plantas es la posibilidad de incorporar mejoras de una forma más rápida, precisa y segura" (Novillo y Costa, División Agrícola de Monsanto, en $A S A J A$, enero 2000, p.35) (la cursiva es del autor).

La afirmación de "las leyes que rigen la naturaleza" refuerza esa sensación de invariabilidad en el tiempo y en el espacio que el pensamiento ilustrado construye precisamente sobre el modelo newtoniano. Por el contrario, los discursos opuestos a la biotecnología cargan el acento en la valoración romántica de los diferentes contextos, ya sean los contextos locales, como acabamos de ver en C.4, ya sean los contextos sociales e históricos:

"A finales del siglo XX no puede tener uno la misma confianza en algunas cosas que las que tenía a finales del siglo XIX, o sea, eso hay que verlo dentro de un contexto, dentro del proceso social general" (C.1) (la cursiva es del autor).

ya sean los contextos estacionales:

"Yo no soy muy mayor pero me acuerdo de cuando las fresas venían de Aranjuez realmente y se comian en una época. Y cómo estábamos comiendo naranjas y plátanos todo el invierno y manzanas y peras que se podían guardar y en un momento determinado estábamos deseando que llegara la fresa, que era lo primero que llegaba, y luego las cerezas que venían del Jerte, y luego las peritas de San Juan, que era cuando iba a empezar el verano, y no comíamos mucho más en invierno, me acuerdo de las ensaladas sin tomate, comíamos mucha legumbre, que le hace falta al suelo, ahora eso lo hemos sustituido por la carne" (C.7) (la cursiva es del autor). 
El tiempo que evoca C.7 (cuya posición es contraria a los OGMs) es bien distinto del tiempo que presentaban los anteriores expertos de Monsanto. El de los expertos es un tiempo que, como la línea recta, atraviesa las diferencias, encadenándolas en una sucesión continua de lo mismo; el tiempo de C.7 es, en cambio, una colección de tiempos cualitativamente diferentes entre sí: el "tiempo de las fresas" no es el mismo que el "tiempo de las naranjas". Además, cada tiempo se asocia intrínsecamente a un lugar: el tiempo que acotan las fresas es un tiempo ligado a Aranjuez, mientras que el definido por las cerezas es un tiempo emparentado con el valle del Jerte. "La carne", en cambio, que hace abstracción del tipo de animal del que proviene y de la parte de él del que se obtiene, que permanece igual a sí misma en cualquier época del año, funciona aquí como metáfora de ese otro tiempo ilustrado con el que "hemos sustituido" el tiempo cargado de diferencias y cualidades.

En lo tocante al papel otorgado a la razón, y en particular a la razón científica, que constituye el cuarto punto, ya vimos cómo "el bando" pro-OGMs tendía a reificarla para convertirla en su aliado retórico más potente. Esta razón abstracta no puede orientarse a captar la variedad y mudanza de lo concreto, sino concentrarse en lo ideal. Eso es lo que presuponen expresiones como "la mejora genética de las plantas" (lo que implica pensar las plantas concretas como imperfectas respecto de la 'planta ideal' ${ }^{10}$ ) o la que citábamos de Vida Rural: "El azar y el desconocimiento frente a la direccionalidad", donde esta dirección no es otra que la que apunta al ideal abstracto del organismo frente a la azarosa falta de un propósito claro en que se mueve la agricultura tradicional.

Esta valoración ilustrada del ideal racional como modelo al que deben tender las cosas reales es la que motiva la crítica de los "anti" de querer convertir la naturaleza en un laboratorio en el que sí pueden producirse esos seres ideales que diseña/descubre la razón científico-técnica:

"Son los problemas que tienen que ver por un lado del convertir con pocas cautelas, con pocas restricciones, ecosistemas enteros o la biosfera como un todo en una especie de gran laboratorio al aire libre, con muy poca idea de lo que va a pasar" (C.1) (la cursiva es del autor).

"Vemos que corporativamente es un ataque directo a la agricultura como la entendemos nosotros, de unión a la tierra, sostenible y duradera, en principio estamos en contra por eso, porque es un ataque directo a nuestra forma de vida. A fin de cuentas un ser vivo de laboratorio se suelta en el campo y se pretende...laboratizar el campo. Para que ese ser vivo funcione hay que llevar el laboratorio al campo, claro, en esas plantas experimentales de laboratorio, pues claro, ahí esta el bicho, funciona o no funciona

${ }^{10}$ Véase sobre esto el magnífico estudio de Van der Ploeg (1990). 
RIS

según los parámetros que tú le pongas. Pero claro, es un ser vivo, con todo lo que eso conlleva de variabilidad de mutaciones, polinizaciones, cruzamientos, hibridaciones... hay muchas variables que se pueden controlar en el laboratorio pero que no se pueden controlar en el campo, es incontrolable" (C.2) (la cursiva es del autor).

De ahí que uno de los elementos "anti"'más reiterados sea la defensa de la biodiversidad, no como resultado premeditado de un diseño de laboratorio (como contra-argumentan los "pro" al afirmar que ellos pueden incluso aumentarla), que no puede más que multiplicar variantes de lo mismo, sino como capacidad natural de producir espontáneamente diferencias y singularidades:

"La violencia inherente a los métodos y metáforas que utilizan las empresas mundiales de la agroindustria y la biotecnología es una violencia contra la biodiversidad de la naturaleza y los conocimientos y la productividad de las mujeres" (V. Shiva, en The Ecologist, enero 2001, p. 37) (la cursiva es del autor).

La reificación ilustrada de ese ideal al que se acaba reduciendo todo lo que focaliza la ciencia se convierte en ocasiones en reificación de la razón científica misma. Cuando el biólogo molecular se enfrenta a sus opositores muestra una imagen de esa razón bien distinta de las idílicas versiones habituales como la visión popperiana de una ciencia en continua revisión o la del escepticismo organizado mertoniano:

"Cuando los temas son estrictamente cientificos, entonces lo que hay es lo que hay. En biología, lo que hay es lo que hay y no hay vuelta de hoja" (F.6) (la cursiva es del autor).

El carácter absoluto de esa razón se pone también de manifiesto en la exclusión, como "irracionales", de cualesquiera otros valores éticos, políticos o de otro orden, que deben siempre supeditarse a aquélla:

"La oposición irracional a esta innovación está de hecho empujando el negocio a las manos de las multinacionales" (F.4) (la cursiva es del autor).

La exclusión, por "irracional", de los planteamientos que puedan hacerse desde cualesquiera otros valores o criterios distintos de esa rotunda verdad que acapara la razón científica lleva lógicamente a la exclusión o, cuando menos, desvalorización de las intervenciones de los no expertos, de sus lenguajes y de sus saberes, identificados como ignorancia:

"Toda innovación merece un debate, pero merece un debate serio, no lo que se está haciendo. Y soy totalmente contrario, y ya me niego, por tanto, a participar a algunas cosas en las que por ingenuidad en el pasado he caído, que es entrar en debates sobre cuestiones técnicas con personas que carecen en absoluto de las credenciales para un 
debate. (...) Porque, claro, lo de informar al consumidor, eso es retórica. El consumidor no está dispuesto a perder dos segundos de enterarse de qué es de lo que se tiene que enterar" (F.4) (la cursiva es del autor).

Los discursos opositores, si bien asumen también la necesidad de información y valoración científicas, no dejan de apreciar también otras formas de razón y conocimiento que, a su juicio, deben tenerse en cuenta:

"Las compañías quieren llevar el debate a un ámbito científico técnico, un debate que la gente no entiende, es el debate ideal en el que intervienen sólo los científicos de 'su lado' -para entendernos - y la gente no puede opinar" (C.4) (la cursiva es del autor).

En casos extremos, se llega incluso a conceder más crédito al saber campesino, basado en la tradición y en la experiencia local contextualizada, que a los hallazgos de la ciencia, aquí desvalorizada en la figura de "algún bioquímico":

"En cualquier caso, la gran esperanza para la agricultura no está en lo que algún bioquímico pueda encontrar en algún tubo de ensayo. Las mayores oportunidades están en lo que los agricultores ya saben o en lo que pueden descubrir en sus tierras" (World.Watch, $n^{\circ} 9,1999, \mathrm{p} .47$ ) (la cursiva es del autor).

En quinto y último lugar, la diferente concepción del tiempo en cada una de ambas posiciones marca una diferencia decisiva. Acabamos de ver cómo "lo que los agricultores ya saben" (el saber acumulado por la experiencia pasada y filtrado por la tradición) es un valor positivo para los "anti" que es también característico del imaginario romántico. En los discursos de los "pro" por el contrario, es el futuro el que tiene valor por sí mismo, pues, siendo el tiempo lugar en el que la razón se desarrolla, éta no puede, sino ir acercándose progresivamente al ideal:

'La biotecnología 'moderna', las plantas del futuro. En las técnicas de modificación genética es donde se identifica la biotecnología moderna, un paso adelante en la biotecnología del futuro por los beneficios que reporta a los consumidores y a los agricultores" (Agricultura, febrero 2002, p.138) (la cursiva es del autor).

Se da por supuesto que las "plantas del futuro" no son plantas abominables, ni amenazantes pues el tiempo avanza hacia lo mejor, hacia el ideal racional. Las plantas ideales del mañana sólo pueden traer "beneficios". En consecuencia, cuanto más atrás en el tiempo, más se aleja uno del ideal, por lo que el pasado es el lugar de lo peor:

"Pensar que el problema del futuro se va a resolver con tecnologías del pasado es nostalgia de ciudad, es decir, la mayor parte de las personas que piensan eso son personas que no han visto lo que es abrochárselas..." (F.4) (la cursiva es del autor). 


\section{RIS}

El futuro se percibe así como un reto que lanza el ideal, que allí se aloja, a la realidad presente, la cual debe modificarse para asemejarse a su forma más perfeccionada:

"Los investigadores agrícolas y los agricultores de todo el mundo afrontan el reto de desarrollar y aplicar una tecnología que permita incrementar los rendimientos, de incrementar los rendimientos de un cereal un 50-75\% durante los próximos 25 años" (Agricultura, abril 2002, p. 345) (la cursiva es del autor).

Por eso los discursos "pro", bajo su apariencia de realismo, son marcadamente prescriptivos, como corresponde al imaginario ilustrado. La "modernización", el "reto del futuro", el ideal a conseguir, imponen un "deber ser", un "tener que" hacer lo que debe hacerse para llegar a hacerlos realidad:

"Para producir cambios significativos que nos permitan reducir el uso de herbicidas, fitosanitarios, de abonos o la posibilidad de cultivar en zonas más salinas, eso tenemos que llegar a la fuerza con la biotecnología" (F. 5).

Para la lógica ilustrada, concebida la idea, ésta ha de realizarse necesariamente, de modo que se haga verdad el ideal hegeliano por el que "todo lo real es racional":

"Aquí tenemos que teneratodas las herramientas posibles y que haya una inteligencia detrás que dice 'pues ahora vamos por este camino, que se produzca pues..."' (F.5) (la cursiva es del autor).

La crítica de los oponentes apunta así a romper esa consecuencia, ese "pues" que sólo se ve como consecuencia lógica si se participa del imaginario ilustrado:

"Lo que se tiene que hacer es consumir el arroz donde se produce, buscar soluciones mucho más sencillas... Creo que no todo lo que se puede hacer tecnológicamente debe hacerse. Se pueden hacer bombas nucleares, pero, ¿deben utilizarse? Cuando nosotros vemos una solución tecnológica lo que tenemos que ver es si hay otras soluciones posibles y analizar los peligros y ventajas" (C.4) (la cursiva es del autor).

Desde esta otra óptica, el futuro no es necesariamente el lugar de lo mejor, allí donde se realiza el ideal:

"A algunos nos gustaría vivir en esta Tierra, no pensamos que sea mejor, digamos, la buena vida del hombre futuro. (...) Bueno, si alguien piensa que la buena vida de la Humanidad es la minería del hombre modificado genéticamente en los fragmentos de Júpiter, allá él, yo tengo otra idea de la buena vida" (C.1) (la cursiva es del autor).

"La biotecnología es sólo un eslabón más en la larga cadena de inventos destinados a sacar el máximo rendimiento de la tierra para hacer ricos a unos cuantos, pobres a la mayoría y legar un futuro de tierras áridas y contaminadas a las generaciones 
futuras" (Montse Escutia, ingeniera agrónoma, en The Ecologist, enero 2001, p.35) (la cursiva es del autor).

Esta imagen de un futuro desolado, habitado por un hombre degradado y una naturaleza monstruosa, acompaña con frecuencia, en el discurso de los "anti", a la constante denuncia de los riesgos imprevistos, de los efectos no deseados, de unos proyectos tecno-científicos que nunca podrán satisfacer su aspiración de control total:

"La alteración de la estructura genética produce a menudo impredecibles efectos no deseados, algunos de ellos observables inmediatamente (por ejemplo en el "supercerdo" al que se le introdujo el gen de la hormona del crecimiento humana se convirtió en artrítico, ulceroso, ciego e impotente(...)" (Ecologistas en Acción, Albacete) (la cursiva es del autor).

A la reiteración de estos recursos retóricos, habitual en los discursos tecnófobos, la ha llamado Mulkay (1993-1994) "retórica del miedo", en oposición a la "retórica de la esperanza" sobre la que se construyen los discursos tecnófilos. En su estudio de "el debate sobre los embriones" mantenido en los años 80 en Gran Bretaña, Mulkay analiza el papel que jugaron ambas formaciones discursivas en las decisiones del Parlamento. La caracterización que hace de cada una de ellas es sorprendentemente afín con los respectivos rasgos románticos e ilustrados que venimos manejando y, en líneas generales, es de total aplicación al debate sobre los OGMs. Para este autor, "la retórica de la esperanza se orienta esencialmente hacia el futuro. El apoyo a la investigación científica se justifica hoy por la firme expectativa de que producirá beneficios significativos más adelante" (Mulkay, 1993-94, p.146), mientras que la "retórica del miedo", cuando avista el futuro, evoca "una visión aterradora de declive moral y de cambios sociales devastadores nacidos de una comunidad científica cada vez más fuera de control" (Ibid p. 147).

De uno y otro caso menudean los ejemplos en muchas de las citas que hemos ido empleando a lo largo del análisis; destaquemos una última en la que la esperanza se vincula directamente con el mito del progreso, uno de los más queridos por la Ilustración:

"Pero esa misma sociedad debe ser consciente que no es razonable oponerse a un progreso que hasta ahora sólo ha rẹndido resultados positivos sin ningún riesgo para el consumidor" (Vida Rural, 1-09-2002, p. 43) (la cursiva es del autor).

\section{CONCLUSIONES}

Hemos tratado de estudiar cómo se desarrolla un debate social en torno a un asunto que se presenta en principio como una cuestión meramente técnica, como son los Organismos Genéticamente Modificados (OGMs). Nuestro objetivo es saber qué 


\section{RIS}

estrategias se utilizan para inducir en la opinión pública ciertas apreciaciones y comportamientos, en función de los distintos intereses y presupuestos de los agentes participantes en el debate.

Para ello suele recurrirse a dos tipos de categorizaciones, cada una de las cuales revela importantes dimensiones del debate, pero también cada una adolece de ciertas limitaciones. Por lo común suele asumirse como válida la visión que los propios agentes tienen del debate, visión que los agrupa en "dos campos" opuestos: el de quienes se oponen a los OGMs (los "anti") y el de quienes los defienden (los "pro"). Esta categorización da por sentados, como si se tratara de hechos puros y duros - y no de presupuestos o valores-, los criterios por los que se establece esa división (en términos de dos bandos beligerantes en torno a la aceptación o rechazo de los OGMs) y no otra. Como decía uno de los "pro", "en cuestiones de ciencia, lo que hay es lo que hay", y es entonces a los otros a quienes toca mover pieza, lo que les lleva necesariamente a ser percibidos como "anti". Que el analista asuma las mismas categorías que esgrimen los sujetos analizados puede ser una decisión ciertamente realista, pero puede también presentar graves deficiencias al mantener en la oscuridad los matices, la complejidad y los presupuestos que los propios sujetos analizados ocultan o ignoran.

La categorización en términos de conflicto entre dos imaginarios sociales, el ilustrado y el romántico, nos permite reconsiderar el debate desde unos criterios que nos sitúan a cierta distancia teórica de los agentes en disputa. Desde este otro enfoque, se revelan nuevos rasgos y, en particular, algunos presupuestos que están por debajo de la superficie del debate que antes habían pasado desapercibidos, como las diferentes maneras con que unos y otros entienden la relación entre "lo natural" y "lo social" o las distintas concepciones del tiempo que subyacen a cada una de las posiciones. Tales presupuestos latentes apelan a presupuestos semejantes que se suponen en los receptores de los distintos discursos y a ellos deben buena parte de su fuerza persuasiva y de su capacidad para modelar la percepción social de este tipo de alimentos.

En este sentido, y aunque la respuesta de los consumidores no es objeto directo de este artículo, cabe conjeturar que sean posiciones ideológicas previas (como, por ejemplo, las anteriormente mencionadas) las que también predeterminen en ellos sus diferentes actitudes. Del fuego cruzado de argumentos a ellos dirigidos no tomarían, entonces, sino aquellos que a posteriori vinieran a reforzar dichos posicionamientos básicos. Sólo se trata, ciertamente de una conjetura, pero es ésa la dirección a la que parecen apuntar algunos estudios sobre la percepción social de la biotecnología ${ }^{11}$.

\footnotetext{
${ }^{11}$ Sobre la imagen social de la biotecnología en España, véase Atienza y Luján (1997), Espeitx (2003) y Luján (2004). En el ámbito europeo, ver Marris et al. (2002).
} 


\section{REFERENCIAS BIBLIOGRÁFICAS}

ATIENZA, J. y J.L. LUJÁN (1997), La imagen social de las nuevas tecnologias biológicas en España, Madrid, CIS, estudio 2213.

BAUMAN, Z. (1997), Modernidad y Holocausto, Madrid, Sequitur.

BERLIN, I. (2000), Las raices del romanticismo, Madrid, Taurus.

BLOOR, D. (1998), Conocimiento e imaginario social, Barcelona, Gedisa.

DÍAZ MÉNDEZ, C. y P. HERRERA (2002), "Un debate en torno a los OGMs", comunicación presentada en el IV Congreso Internacional de Antropología, Barcelona.

DOMÉNECH, M. y F. J. TIRADO (1998), Sociología simétrica. Ensayos sobre ciencia, tecnología y sociedad, Barcelona, Gedisa.

ESPEITX, E. (2003), Los organismos genéticamente modificados: del debate social a la opinión pública (documento inédito).

FOUCAULT, M. (1969), La arqueología del saber, Madrid, Siglo XXI.

FOX KELLER, E. (1991), Reflexiones sobre género y ciencia, Valencia, Ed. A. El Magnánimo.

HERRERA, P. (2003), Tecnofilia y tecnofobia como imaginarios colectivos. El caso de los OGMs (documento inédito).

IBÁÑEZ, T. (2001), Municiones para disidentes. Realidad, verdad, politica, Barcelona, Gedisa.

LIZCANO, E. (1999), “La metáfora como analizador social”, Empiria, n 2, pp. 29-60.

LUJÁN, J.L. (2004), "Sobre las imágenes sociales de la ciencia. Ciencia en general frente a aplicaciones concretas en el caso de la biotecnologia", Sistema, n 179-180, pp. 123-133.

MARRIS, C. et al. (2002), Public Perception of Agricultural Biotechnologies en www.inra.fr.

MULKAY, M. (1993-1994), "Retórica y control social en el gran debate sobre los embriones", Politica y Sociedad, no 14/15, Madrid, pp. 143-153.

PLOEG, J. D. Van der (1990), "Sistemas de conocimiento, metáfora y campo de interacción: el caso del cultivo de la patata en el altiplano peruano", Agricultura y Sociedad, n 56, pp. 143-166.

TODT, O. (2003), "La gestión social de la ingeniería genética", Revista Internacional de Sociología, $\mathrm{n}^{0} 34$, pp. 65-80.

(2004), "El conflicto sobre la ingeniería genética y los valores subyacentes", Sistema, n 179-180, pp. 89-102. 